(2014) Learning Analytics Research, Theory and Practice: Widening the Discipline. Journal of Learning Analytics, 1 (3), 4-6.

\title{
Learning Analytics Research, Theory and Practice: Widening the Discipline
}

\author{
Abelardo Pardo ${ }^{(1)}$ and Stephanie Teasley ${ }^{(2)}$ \\ ${ }^{(1)}$ University of Sydney, Australia \\ ableardo.pardo@sydney.edu.au \\ ${ }^{(2)}$ University of Michigan, USA \\ steasley@umich.edu
}

\begin{abstract}
This article introduces the special issue presenting five papers from SoLAR's Learning Analytics and Knowledge 2014 conference. The authors of these papers were invited to expand their original papers to provide a more in-depth view of their work and one that would reach out to a broad audience. The papers included here provide a view into the diversity of LA research presented at LAK 14 and demonstrate exciting new avenues by which the field is expanding. We believe that the papers presented here move the field ahead by contributing to a wider discourse about how we can effectively and ethically utilize "big data" to inform learning research and theory, and the resulting practices that support learning.
\end{abstract}

KEYWORDS: LAK14, Learning Analytics and Knowledge Conference, SOLAR, Society for Learning Analytics Research, Special issue

\section{EDITORIAL - SPECIAL ISSUE}

In March, 2014, we had the pleasure of serving as co-chairs for the fourth meeting of the conference, Learning Analytics and Knowledge (LAK 14). The theme of the conference, the "Intersection of Learning Analytics Research, Theory and Practice," represented the location of the meeting-- Indianapolis, called The City at the Crossroads of America" -- as well as our intent to select papers that represented the intersection of basic research on learning, learning theory, learning technology, and educational practice. The response to this call and the ensuing peer review process resulted in the publication as conference proceedings of 12 full papers, 26 short papers and 4 panel sessions, representing authors from 26 countries.

The papers included in this special issue of the Journal of Learning Analytics present our selection of five of the best papers presented at LAK 14. For this issue, we invited each set of authors to reach out to a broad audience and expand on their original conference paper. We held them to strict criteria for building on the existing conference paper (published by the ACM in the conference proceedings) and the new work was submitted for an additional round of external reviews. We are gratified by the results as the authors rose to this challenge and provided us with papers we believe will have lasting value to the field in this expanded form. 
(2014) Learning Analytics Research, Theory and Practice: Widening the Discipline. Journal of Learning Analytics, 1 (3), 4-6.

\subsection{Widening of the Discipline}

While special issues of journals typically focus on a particular methodology or a research topic, this "Best of" collection departs somewhat from that path. The papers we have included in this issue demonstrate the widening of concerns in the area of Learning Analytics (LA). The term Analytics generally describes the discovery and communication of meaningful patterns in data, when we talk about Learning Analytics we aim for discovery and communication about learning that is not only meaningful but also actionable. In an early stage of the field, much of the research was aimed at improving student retention, and analytics were conducted in service of designing interventions that would allow institutions to achieve this outcome. However, looking solely at learning outcomes does not get us closer to understanding the process of learning, which is the great promise of the kind of "data exhaust" generated by today's technology. Fortunately, the field is evolving quickly and one measure of this growth is the increasing breadth of methodologies being applied to learning-related data sources. What we do with this data, how we link it to other sources of data held by educational institutions (e.g., admissions data, registrar's data on course sequences) and how we connect this setting with learning scenarios allows for a much broader impact of LA on students, instructors, programs, and institutions. The papers in this issue provide a view into the diversity of LA research presented at LAK 2014 and demonstrate exciting new avenues by which the field is expanding.

\section{THIS ISSUE}

The first three papers in this issue rely on log data generated from student use of online learning systems to demonstrate the value of applying established statistical methodologies typically associated with other kinds of data sources and identify actions to improve the learning experience. The first paper, by Aguiar, Ambrose, Chawla, Goodrich \& Brockman (2014) uses student-level log data from an ePortfolio platform to diagnose student engagement. They demonstrate the viability of their approach by applying classification methods and correlating their outcomes with student performance outcomes. The second paper, by Hecking, Ziebarth \& Hoppe (2014) adapted methods from Social Network Analysis and describes students' use of online learning resources use as a bipartite network (Wasserman \& Faust, 1994). This methodology reveals the variation of student-resource patterns to identify popular course resources, as well as to identify who uses them and how this use pattern changes over time. Such information can be used not only to help instructors make decisions about their course materials, but also to understand how students clustering around specific resources can create learning subcommunities that may be leveraged for peer-to-peer learning activities. In the third paper, Chiu \& Fujita (2014) use content analysis techniques from the field of Computer Supported Collaborative Learning (Weinberger \& Fischer, 2006) and applied Statistical Discourse Analysis (Wise \& Chiu, 2012) to data drawn from online forums. Their paper specifically addresses potential analytic difficulties associated with this kind of data and uses a case study approach to demonstrate how these methods can build our understanding of student learning achieved through online discourse. 
The final two papers in this issue step away from student-generated log data to address questions that affect academic decision-making at the course and institutional level. The fourth paper, by Mendez, Ochoa \& Chiluiza (2014) apply a number of methodological techniques on program-level historical data to identify the various properties of courses (e.g., difficulty, inter-course dependence, and curriculum coherence). They use these analyses to diagnose problems and opportunities for curricular re-design within individual academic programs. This perspective moves away from the emphasis on issues associated with specific courses to provide a more systematic approach to designing the larger sequence of courses constituting a degree program. Finally, the paper by Ferguson, Macfadyen, Clow, Tynan, Alexander \& Dawson (2014) addresses the very real challenge of large-scale adoption of LA in academic institutions. These authors explicate tools and case studies to show how the Rapid Outcome Mapping Approach developed for complex systems (ROMA model; Young \& Mendizabal, 2009) can be applied to guide the institutional implementation of learning analytics. This paper provides a valuable step-by-step approach that should be of interest to stakeholders at all levels within the academy, from students and instructors to provosts and presidents.

\section{CONCLUSION}

The papers included in this special issue clearly show how the field of Learning Analytics is broadening significantly beyond the initial focus on student retention. Analytics are now being explored in a much richer variety of contexts and encouraging results are obtained pointing at the potential for the discipline to have a significant impact in education in general. We hope that the papers presented here move the field ahead by contributing to a wider discourse about how we can effectively and ethically utilize "big data" about learning. Opening up our research to include the very best methods borrowed from our colleagues outside the LA community and aiming our work to address issues of interest to all members of the academic community will help us to collectively expand the impact of our field. Our work needs to be able to thoughtfully inform learners, educators, and policy makers so we can help learning to be more accessible and effective for everyone.

\section{REFERENCES}

Wasserman, S. \& Faust, K. (1994). Social Networks Analysis: Methods and Applications. Cambridge: Cambridge University Press.

Weinberger, A., \& Fischer, F. (2006). A framework to analyze argumentative knowledge construction in computer-supported collaborative learning. Computers \& Education, 46(1), 71-95.

Wise, A. F., \& Chiu, M. M. (2012). Statistical Discourse Analysis of a Role-Based Online Discussion Forum: Patterns of Knowledge Construction. Proceedings of the 45th Hawaii International Conference on System Sciences, 3378-3386.

Young, J. \& Mendizabal, E. (2009). Helping researchers become policy entrepreneurs. Overseas Development Institute, Briefing Paper \# 53. Available at http://www.odi.org/publications/1127become-policy-entrepreneur-roma. 